\title{
Data issue considerations for the monitoring and evaluation of natural resources and the environment - a case study of Shangri-La County, Yunnan Province, China
}

\section{Rencai Dong, Ting Li, Yuliang Li, Tianqi Jiang, Siyuan Li, Yan Yan \& Qing Li}

To cite this article: Rencai Dong, Ting Li, Yuliang Li, Tianqi Jiang, Siyuan Li, Yan Yan \& Qing Li (2015) Data issue considerations for the monitoring and evaluation of natural resources and the environment - a case study of Shangri-La County, Yunnan Province, China, International Journal of Sustainable Development \& World Ecology, 22:2, 178-183, DOI: 10.1080/13504509.2014.923541

To link to this article: http://dx.doi.org/10.1080/13504509.2014.923541

曲 Published online: 03 Jun 2014.

凹 Article views: 96

View Crossmark data ¿
Submit your article to this journal $₫$

View related articles

Citing articles: 3 View citing articles $\sqsubset$ 


\title{
Data issue considerations for the monitoring and evaluation of natural resources and the environment - a case study of Shangri-La County, Yunnan Province, China
}

\author{
Rencai Donga ${ }^{\mathrm{a}}$, Ting $\mathrm{Li}^{\mathrm{a}}$, Yuliang Li ${ }^{\mathrm{a}}$, Tianqi Jiang ${ }^{\mathrm{a}}$, Siyuan $\mathrm{Li}^{\mathrm{a}}$, Yan $\mathrm{Yan}^{\mathrm{a} *}$ and Qing $\mathrm{Li}^{\mathrm{b}}$ \\ ${ }^{a}$ State Key Laboratory of Urban and Regional Ecology, Research Center for Eco-Environmental Sciences, Chinese Academy of \\ Sciences, Beijing 100085, China, ${ }^{b}$ Department of Mathematical Science, Xi'an Jiaotong-Liverpool University, Jiangsu Province \\ 215123, China
}

(Received 11 December 2013; final version received 9 April 2014)

\begin{abstract}
The county-governed administrative area considered in this study is a unit with wide distributed basic geographical characteristics in China. In addition, the area is the basic organizer and manager of the monitoring and evaluation (M\&E) system of the natural resources and environment (NRE) of China. To enhance the reliability and sustainability of the M\&E system subjected to the NRE, the researchers should focus on the data sources and emphasize the data qualities that are of concern to various stakeholders. In this paper, an in-depth metadata analysis, based on the M\&E indicator system of the NRE, is composed of two approaches and a typical practical case: (1) metadata tracking approach - generate the core parameters of each indicator, such as the publisher, the creator, the coverage, the update cycle and type; (2) questionnaire survey approach - invite some scholars, consultants and citizens to evaluate the feasibility and the accessibility of the data sources of the 22 preset M\&E indicators and (3) practical case - acquire the data sources of the dynamic monitoring of NRE in Shangri-La County, Yunnan Province, China, including a backward economy and imperfect statistical systems. The goal of this research is to explore the basic status of $\mathrm{M} \& \mathrm{E}$ data of one vast county-governed area in China, with the hope to improve the stability of the M\&E system of the NRE at the county level.
\end{abstract}

Keywords: metadata; monitoring and evaluation; natural resources and environment; dynamic monitoring; Shangri-La County

\section{Introduction}

Taking a comprehensive overview of the nationwide circumstances and political framework of China, countygoverned administrative areas account for over 90\% of mainland China. Those counties, the population of which accounts for over $80 \%$ of the total population, are the key targets of natural resource management, environmental protection and ecological restoration (Chou 2003). Not only do those counties play vital roles in China's urbanrural integration, but they also fulfill a significant function in the National Sustainable Development Strategy (Zhao et al. 2013). Therefore, the supervisory control and evaluation of the natural resources and environment (NRE) of a county are of practical significance. In the new millennium, imperfect statistical systems and insufficient data management cause a bottleneck in the development and regulation of the NRE. In recent years, the monitoring and evaluation (M\&E) of the NRE has been implemented by some county governments, and comprehensive $\mathrm{M} \& \mathrm{E}$ indicator systems for the counties have been continuously improved. Furthermore, the Chinese government has focused on improving the system of property rights and supervising the misuse of authorities to register natural resources, such as water bodies and forests.

Many studies have already explored the evaluation methods and the indicator systems to measure the NRE in China. The following are some fundamental principles selected to assess the indicators that are widely accepted:

(1) Data availability: it is required that the data sources should be open and user-friendly. The difficulty in collecting and quantifying the data and indicators must be low enough to permit practical use of the indicator.

(2) Temporal continuity: the historical data should be continuous, and the dynamic changes should be as specific as possible. In addition, indicators should capture long-term rather than short-term processes.

(3) Comparability: to guarantee the full comparability between different counties, researchers should collect data within the same period and apply the same method. Moreover, the comparison of results must not be affected by factors other than the indicators ( $\mathrm{Li}$ et al. 2009).

In fact, the M\&E of the NRE of a county may involve many multisource and heterogeneous indices, especially the environmental information and the statistical information. Environmental information consists of soil, air, noise and water qualities, whereas statistical information includes population, living, social and economic situations. To ensure that the final evaluation results are 
effective and scientific, it is a top priority to guarantee the accuracy, comprehensiveness and timeliness of the data (Boström 2012). This paper therefore focuses on the metadata issue by considering a typical case study of ShangriLa County to popularize a more stable and comprehensive assessment system for use in other counties.

\section{Study methods}

\subsection{Metadata tracking method}

Metadata is defined as 'data about data' and it is relevant in two conceptually different areas. One area is structural metadata, more properly called 'data about the containers of data,' which considers the design and specification of data structures; the other area is descriptive metadata, which considers individual instances of application data and the data content. In other words, structured information has the function of describing, explaining and locating information resources, and descriptive information explains the content, quality, condition and other relevant characteristics of the data (Long et al. 2010).

Achieving a comprehensive assessment of the NRE in different counties is one of the key objectives to evaluate the natural resources of county-governed administrative areas. Those assessments and indicators aim to produce and communicate information that is required for evidence-based policy-making, strategic planning and learning. To obtain the desired effects, indicators must be relevant and reliable; moreover, they must be communicated to the appropriate audience at the appropriate moment and in the appropriate manner (Lyytimäki et al. 2013). To enhance the reliability and scientific rigor of the assessment results, the entire data sources involved in the M\&E should have unified criteria and background information.

The standardization of the data of the M\&E has always been the focus of attention. In the early part of this century, the metadata standard was established in China for sharing information on sustainable development, aiming to strengthen the management efficiency of the shared data at the national level. The core parameters of the metadata on sustainable development consist of the content, quality, status, identifier and other relevant characteristics. Although the metadata standard could be utilized for the description of a data set at the national level, for the county level, a standard is still scarce.

This paper focuses on identifying, tracking and generating the core metadata in the M\&E system of the NRE of Shangri-La County. The Dublin Core Metadata (DCM) was selected as the main method because it can be used for multiple purposes, such as simple resource description, combining the different metadata standards and providing the interoperability for metadata vocabularies. The Simple Dublin Core Metadata Element Set is composed of 15 metadata elements: (1) title, (2) creator, (3) subject, (4) description, (5) publisher, (6) contributor, (7) date, (8) type, (9) format, (10) identifier, (11) source, (12) language,
(13) relation, (14) coverage and (15) rights (Dublin Core Metadata Initiative 2013). Those core parameters are suitable for the M\&E system of the NRE, especially (8) type, (2) creator, (5) publisher, (11) source, (14) coverage and (7) date. Those core metadata elements have been generated for use on the data of Shangri-La County.

\subsection{Questionnaire method}

The scientific objective of M\&E is to measure the status and trends of the NRE among the research workers, government departments and the public. Thus, the availability of the data should be included as a major point in the questionnaire. To assess the difficulty of obtaining the data via different indicators, four options, namely $\mathrm{A}, \mathrm{B}, \mathrm{C}$, and $\mathrm{D}$, are inscribed into the survey. Researchers can determine which of the following option is the most suitable according to the accessibility of the data.

Option A: the data exist and are open. Moreover, they can be obtained through searching the local yearbooks or government websites;

Option B: the data exist but are not open and can be obtained by contacting the appropriate agencies for free or with a pay-to-use system;

Option C: the data exist but are not open, and it is difficult to obtain them by contacting the appropriate agencies;

Option D: the data do not exist, and self-investigation and monitoring are required.

This study implemented several investigation methods, including phone calls, emails and face-to-face interviews. They all required the respondents to fill in the questionnaires based on their own actual experience.

A total of 100 questionnaires were distributed, and 78 of them were valid. The final statistical results are presented in Table 1.

\section{Practical case in Shangri-La County}

\subsection{General information of Shangri-La County}

Shangri-La County is located in the northwest of Yunnan Province, as well as in the southern margin of the Tibetan Plateau. Shangri-La County is the central region of the world-famous scenic spot, 'Three Parallel Rivers' (He 2003). The entire county includes two towns and nine townships, with a total area of $11,613 \mathrm{~km}^{2}$ and consists of tens of minorities, such as Naxi, Yi, Bai and Tibetan. The population density of the county is nearly 10 persons per square kilometer. The multiethnic gathering brings Shangri-La County abundant cultural resources, such as the historic Tea-Horse Road, massive national culture, folk landscapes with distinguishing features and magnificent natural sceneries. These cultural resources are integrated skillfully, giving Shangri-La County a great reputation, with titles such as the 'Final Frontier of Mankind,' the 'Pearl of the Plateau' and the 'Moon in Heart.' 


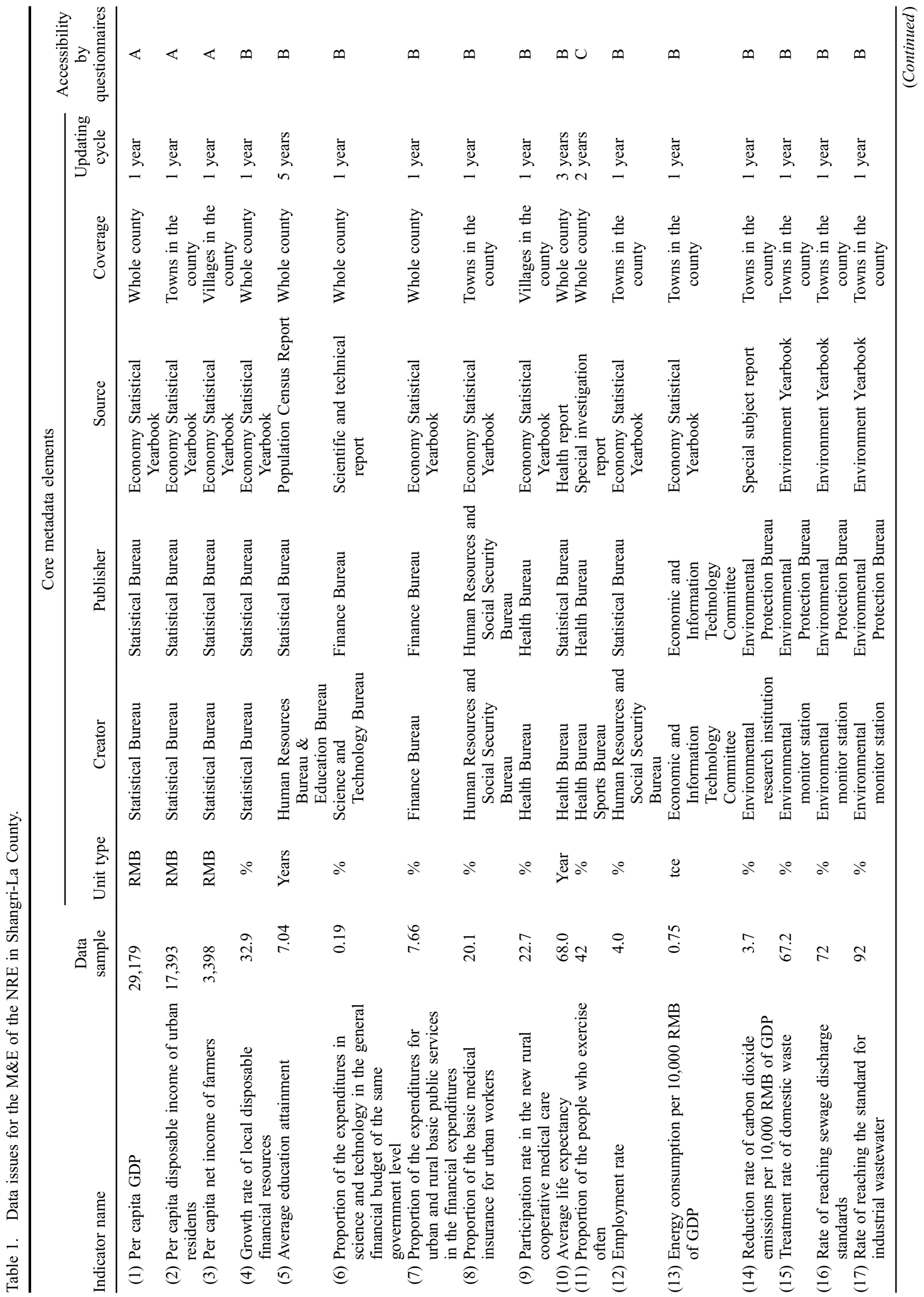




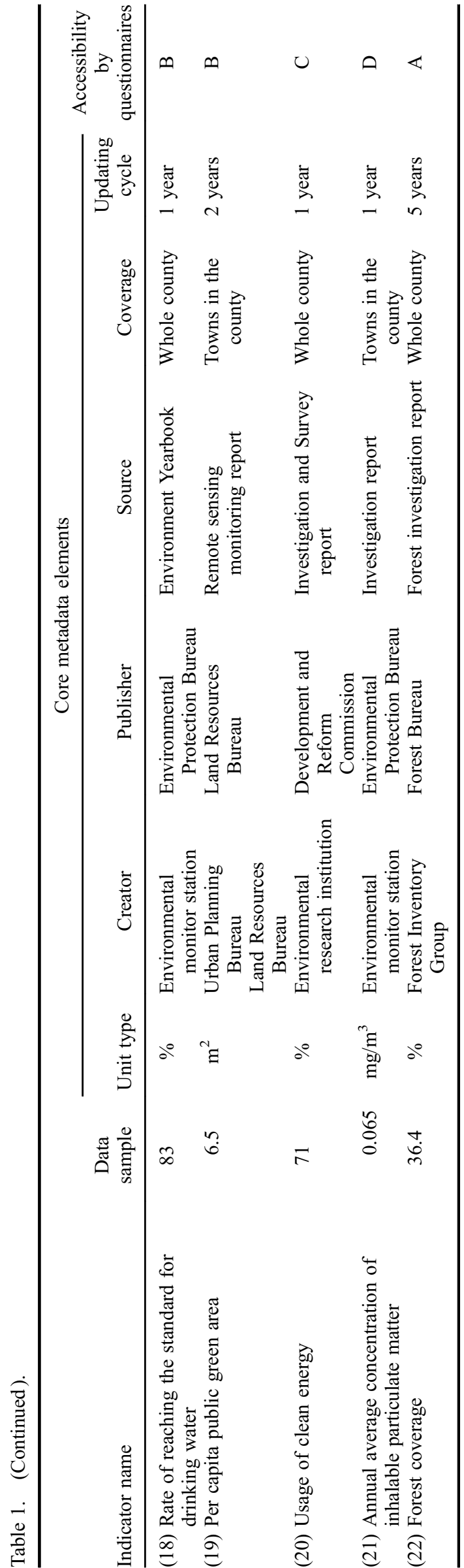

The climate in Shangri-La County is complex and changeable, and the natural ecological conditions in the county are healthy. In the virgin forest, there are a large number of rare birds and animals, such as golden monkeys, pandas, wild bears, black musk deer and leopards. Moreover, there are numerous rare medicines and valuable ornamental plants, in particular wild edible mushrooms. To regulate the market transaction of bulk wild mushrooms, the county government developed a trading market to protect the wild edible mushrooms from excessive picking. In addition, Shangri-La County is also rich in mineral resources, with pervasive high altitude mines.

The recent utilization and protection of the NRE has gained some preliminary progression. Priority was placed on the exploitation of the water resources and tourism resources. Moreover, green industry has also expanded vigorously, along with bio-industry and tourism. Simultaneously, three key projects have been established in the county's economic and environmental development: the resource and environment protection project, the development project and the action project (Qi et al. 2000). Admittedly, the local tertiary industries are undergoing healthy development, with tourism as the pillar industry.

To achieve 'sustainable development and ecological integrity,' contemporary natural resource management aims to espouse the demands of biodiversity conservation from the needs of the local people's livelihood. As a result, the local government is focusing more attention on the M\&E work of the NRE.

\subsection{Metadata analysis for M\&E in Shangri-La County}

Based on a previous study, obtaining the data for the M\&E of the NRE in an ordinary county is quite difficult. However, the generation of metadata for each indicator data is even more difficult to accomplish. It is a significant challenge to collect detailed information for each piece of data. Table 1 reveals some core elements of each indicator of the M\&E system.

Table 1 contains 22 indicators, and for each indicator, there are 6 core elements: unit type, coverage, creator, publisher, sources and updating cycle. The characteristics of each core element are described as follows:

(1) Unit type: starting from the third column is the unit type of each indicator. With a glance at this column, different indicators are expressed in diversified units, such as percentage, year, RMB and area, i.e., each indicator is measurable, so data could potentially be generated by metadata.

(2) Coverage: the table contains data within the range of an administrative county. As each indicator may cover a particular area, the Shangri-La County is classified into three areas: villages in the county, towns in the county and the entire county. The indicator system of the M\&E approach should reflect the spatial characteristics of the NRE. 
(3) Creator: all of the 22 indicators are provided by local government departments or their branch organizations, which indicates that the authorities are the primary data providers. Generally, statistical bureaus in China provide most of the data on which the assessment of the NRE relies. However, more than 15 bureaus or departments participate in the data collection, only accounting for $27 \%$ of all of the 56 Shangri-La-County-governed bureaus or departments. Such numerous divisions could be a huge obstacle for some small M\&E projects. In addition, some special indicators, such as the reduction rate of carbon dioxide emissions per 10,000 RMB of GDP and the usage rate of clean energy, can only be achieved by scientific research institutions and professional investigation organizations; thus, those indicators are not stable in the data sources.

(4) Publisher: all of the 22 indicators were published by the local statistical departments. Therefore, the statistical bureaus play a key role as the publisher, and almost all of the data regarding the NRE require their approval.

(5) Source: the data for nine indicators are released by the statistical departments in the form of the Economic Statistical Yearbook via texts and websites. Other indicators are obtained through population census reports, scientific and technical reports, health reports, environment yearbooks, remote sensing monitoring reports, forest investigation reports and so on. This situation indicates the multisource character of the data sources in Shangri-La County.

(6) Updating cycle: the update period of the data for 15 indicators is 1 year. Other indicators are determined by some special activity, such as forest investigation, with remote sensing monitoring in 2-, 3- and 5-year periods. Therefore, the suitable update cycle of the dynamic monitoring on the NRE may be 1 year. However, the data for 2, 3 and 5 years should be transformed into the 1-year format for comparison.

The problem is that some indicators are compound indicators, e.g., modeled by several other parameters, and those parameters themselves have sources, publishers and so on. For example, No. 14 (reduction rate of carbon dioxide emissions per 10,000 RMB of GDP) involves two aspects: industrial process and economic development; its parameter should reflect the carbon emission and the annual GDP of this county. In addition, No. 19 (per capita public green area) is generated by two parameters: one parameter is the total greening area, and the other is the population of this county at the end of the year. Therefore, these metadata of indicators are more complicated in practice than the indicators considered in this research.

\subsection{Accessibility analysis by questionnaires}

A total of 100 questionnaires regarding the data availability were issued to students, researchers and citizens.
Subsequently, 89 copies were collected, and 78 of them were valid. In the last column of Table 1, the result of each indicator is presented. From the table, only four indicators of all 22 indicators are characterized as option A, i.e., those indicators' data can be used freely and easily from the local yearbooks or government websites; 15 indicators' data accessibilities belong to option B, i.e., the data are obtained by appropriate agencies with a cost or for free; option $\mathrm{C}$ contains only two indicators, and the data are difficult to obtain by contacting the appropriate agencies; finally, one indicator is characterized by option $\mathrm{D}$ because the annual average concentration of inhalable particulate matter does not exist and requires special investigation by an environmental institute.

Most of the data can be collected from the China Statistical Database of Economic and Social Development in the China National Knowledge Infrastructure (CNKI). The CNKI is a large statistical yearbook database, which is established for statistical data inquiry, data mining and analysis as well as personal data management. All of the authoritative statistics yearbooks have been digitized, integrated and published on a large scale. Currently, the CNKI is the primary data source for the county's M\&E information system of the NRE.

\section{Conclusion and discussion}

The M\&E system of a county's NRE is a complex project, which consists of a set of indicators, such as the economy, society, resources and environment. Previous studies suggested that there was considerable difficulty in acquiring data to monitor the indicators dynamically. First, the core elements describing most data are difficult to obtain, resulting in the inferior features of data, such as instability, unreliability and unavailability. Second, the data lack openness and transparency, thereby restricting the fairness of the assessment. Therefore, much work is required to ensure data availability.

From this study, increasing the quality of the data reflecting the M\&E indicators of the NRE in a county is recommended through the following means:

(1) Establishing a county-governed policy on the 'Data Center for the Natural Resources and Environment' to make the data as well as metadata available to the public: the previous data provider or publisher can provide the data directly to the Data Center. In the future, the Data Center can be regarded as the unified data creator and the data sharing network and the network as the only data production method. Once the Data Center is established, the data producer and the production mode could be unified and standardized (Wang et al. 2013), thereby making it convenient for the subsequent data detection and collection in the study of the M\&E of the local NRE.

(2) Further improvement of the authenticity and objectivity of the data: led by the local government, a sustainable data auditing team shall be 
arranged to audit the authenticity of the data by random sampling in the survey after the team fully understands the features of the data statistics.

(3) Increasing the frequency of data updating: currently, most of the data in the county are produced by the national statistical agencies and are released in the form of a yearbook, which is updated once a year and determines the maximum frequency of the dynamic monitoring of the NRE in a county. After the local unified data creator (Data Center) appears, all of the data publishers can appropriately improve the frequency of data submission to increase the efficiency of the dynamic monitoring of the local NRE.

\section{Acknowledgement}

This study was supported by the Supporting Program of the 12th Five-Year Plan for Science and Technology Research of China (2013BAJ04B03, 2011BAC09B08).

\section{References}

Boström M. 2012. The problematic social dimension of sustainable development: the case of the forest stewardship council. Int J Sustain Dev World Ecol. 19:3-15. doi:10.1080/ 13504509.2011.582891
Chou F. 2003. On comprehensive evaluation of county sustainable development. Econ Geogr. 23:319-326 (in Chinese).

Dublin Core Metadata Initiative. 2013. Dublin core metadata element set, Version 1.1 [Internet]. [cited 2013 Apr 5]. Available from: Dublincore.org

He Y. 2003. Brief talk on the sustainable development of Diqing district. Yunnan Environ Sci. 22:23-26 (in Chinese).

Li F, Liu X, Hu D, Wang R, Yang W, Li D, Zhao D. 2009. Measurement indicators and an evaluation approach for assessing urban sustainable development: a case study for China's Jining City. Landsc Urban Plan. 90:134-142. doi:10.1016/j.landurbplan.2008.10.022

Long J, Chen S, Liu G. 2010. Metadata representation and management in the scientific assessment system. Comput Technol Dev. 20:12-15 (in Chinese).

Lyytimäki J, Tapio P, Varho V, Söderman T. 2013. The use, nonuse and misuse of indicators in sustainability assessment and communication. Int J Sustain Dev World Ecol. 20:385-393. doi:10.1080/13504509.2013.834524

Qi Z, Cheng S, Shen L. 2000. A Shangri-La strategy for sustainable development and its practice in the Qinghai-Tibet Plateau. Resour Sci. 22:83-85 (in Chinese).

Wang H, Zhang T, Quan Y, Dong R. 2013. Research on the framework of the environmental internet of things. Int $\mathrm{J}$ Sustain Dev World Ecol. 20:199-204. doi:10.1080/ 13504509.2013.783517

Zhao J, Zheng X, Dong R, Shao G. 2013. The planning, construction, and management toward sustainable cities in china needs the environmental internet of things. Int $J$ Sustain Dev World Ecol. 20:195-198. doi:10.1080/ 13504509.2013.784882 